\title{
Successful transitioning of a conventional slurry tailings storage facility for central thickened discharge
}

\author{
DA Accadia Golder Associates Pty Ltd, Australia \\ FW Gassner Golder Associates Pty Ltd, Australia
}

\begin{abstract}
A copper mine in Australia operated a perimeter discharge tailings storage facility (TSF) for storage of conventional slurried tailings. In response to regional water shortages, the mine installed a high-rate thickener to dewater the tailings. This provided an opportunity to transition the perimeter discharge TSF for central thickened discharge (CTD).

To facilitate the transition, an interim TSF was designed for storage of thickened tailings from the newly commissioned thickener, allowing tailings in the existing TSF to undergo a period of drying and consolidation. During deposition in the interim TSF, a retrofit design was prepared for the existing TSF to allow it to receive centrally deposited thickened tailings while optimising water recovery from the TSF.

This paper describes details of the retrofit, including geotechnical and water management considerations and optimisation of the storage layout to ultimately form a dual-mounded system for tailings deposition. The dual-mounded layout provides flexibility for cycling of tailings deposition and facilitates perimeter embankment raise construction in phases. The paper describes the design, construction and operational stages of the successful transitioning of the facility.
\end{abstract}

Keywords: central thickened discharge, thickened tailings, water management, tailings storage facility

\section{Introduction}

CSA Mine in Cobar, New South Wales was faced with water supply constraints in the mid-2000s due to widespread extended drought conditions in the country. The mine operates at an annual production rate of approximately $1.15 \mathrm{M} \mathrm{t}$, producing approximately 800,000 dry tonnes of tailings annually. Approximately $60 \%$ of the tailings are used for underground backfill. The remainder of the tailings was, up until the mid-2000s, hydraulically deposited in a TSF at a slurry solids concentration of approximately $30 \%$ by weight. The mine relied on water supplied by the Cobar Water Board. Due to regional water shortages after prolonged drought, CSA Mine was forced to reduce its reliance on the town's water supply. A tailings dewatering options study was subsequently undertaken to assess options to reduce water consumption, the largest of which was related to tailings discharge. The technical and cost-based assessment concluded that a high-rate thickener, that would thicken the tailings to approximately $50 \%$ by weight, would significantly reduce the reliance on the town's water supply.

\section{$2 \quad$ Background}

\subsection{Mining operation and tailings generation}

CSA Mine (the site) produces copper concentrate and silver from the processing of ore mined by underground methods. The ore is hosted in siltstone and sandstone, and the specific gravity of the ore is typically around 2.8. Mining is via longhole open stoping and the ore is milled and processed at the surface by flotation circuit. Copper concentrate is transported offsite for refinement and tailings is managed at the site by a combination of underground backfill and surface tailings deposition. Backfill is undertaken on a campaign basis. The method employs cyclones to separate the coarse fraction before addition of cement and pumping to 
backfill stopes. Cyclone overflow is transferred to the tailings thickener where it is flocculated to improve the thickening process. Since the introduction of the thickener, underflow has been pumped to the TSF at a typical slurry solids concentration of $50 \%$ by weight (equivalent slurry density of approximately $1.5 \mathrm{t} / \mathrm{m}^{3}$ ). More recent improvements have resulted in solids concentration approaching $60 \%$.

The milling process typically results in tailings particles finer than 100 microns. During times of backfill operation, classified tailings and potentially a portion of total tailings, subject to backfill plant demand, is discharged to the TSF. When the backfill plant is not in operation, total tailings is discharged. The operation of the backfill plant alters the tailings deposition performance in the TSF by changing the tonnage rate, solids concentration, discharge velocity and particle size of the tailings. Average dry density of tailings in the TSF currently varies between approximately 1.2 and $1.4 \mathrm{t} / \mathrm{m}^{3}$. Beach slope gradients achieved at various stages of the operation are described in this paper.

\subsection{Existing tailings storage facilities}

The site comprises two adjoining tailings storages - the South TSF and the North TSF, covering areas of approximately 80 and 110 ha respectively. The South TSF, the only storage operated by the mine and focus of this case study, abuts the North TSF on its northern side. The perimeter embankment was initially formed with compacted clay and rockfill in the 1960s. The embankment upstream was raised on four occasions with compacted clay and then raised with compacted tailings sourced from the impoundment area. A layout plan of the TSFs, as at 2004, is presented in Figure 1.

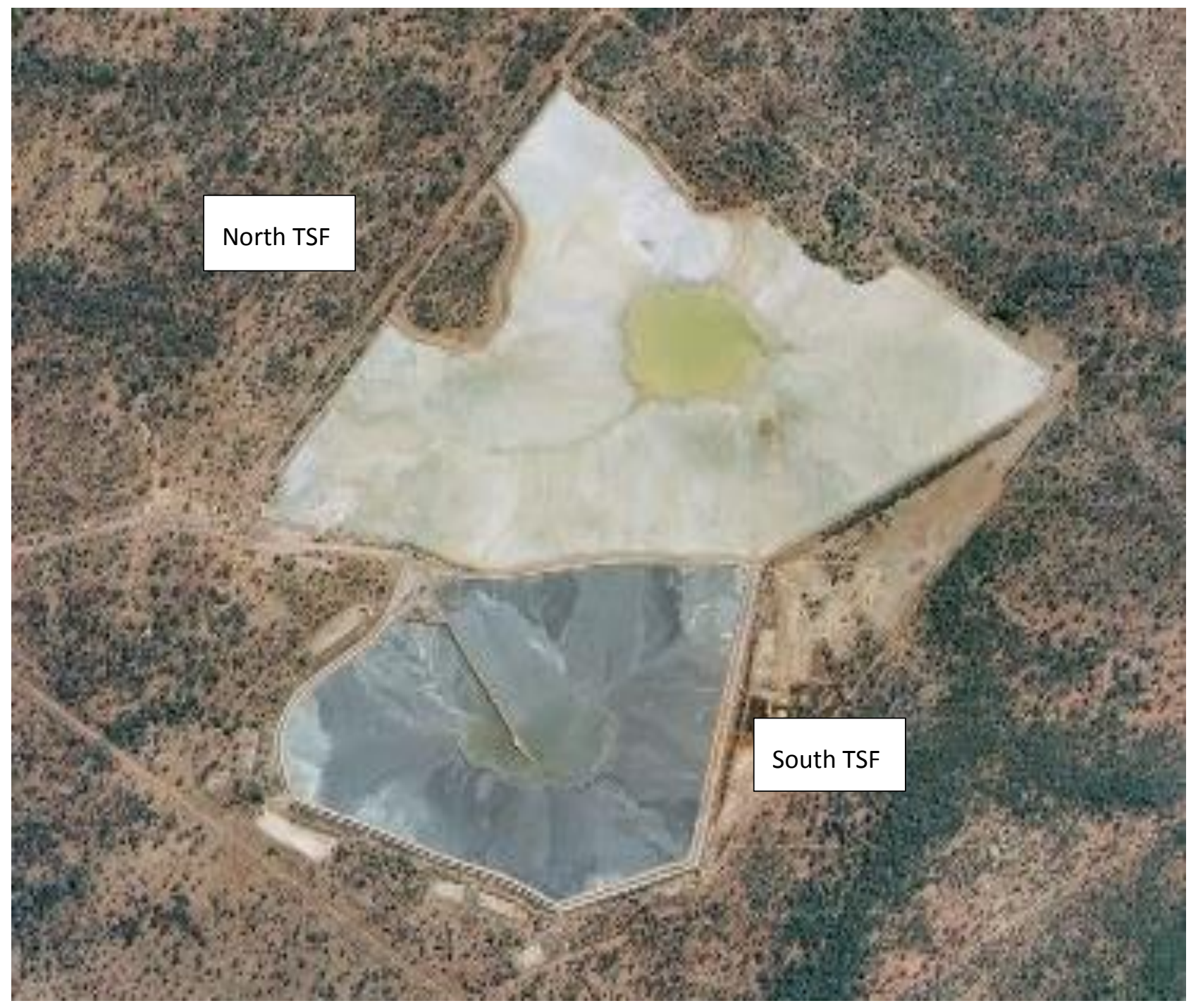

Figure 1 Aerial photograph of the site TSFs, dated August 2004 
Prior to its transition to CTD, operation of the South TSF faced a number of challenges, namely:

- Management of pond location and size. The pond would often deviate from its central position and at times migrate to the upstream edges of the perimeter embankment.

- A high phreatic surface. The size of the supernatant pond was variable and at times would extend to the perimeter embankment, leading to the potential for a high phreatic surface to develop.

- Inefficient return of supernatant water. The shallow supernatant pond of water would be difficult to pump from and resulted in large evaporation losses.

\subsection{Life-of-mine storage study}

A life-of-mine tailings storage study was undertaken that considered the change in slurry density and available sites for storage. The study concluded that conversion of the South TSF to a CTD layout was the preferred option on the basis of environmental and cost considerations. Land clearing for the CTD layout was limited to the interim storage area and the decant dam area, where development of a new site would have required clearing a considerably larger area. Additional rehabilitation works at closure would also be required if an additional site was developed. The CTD layout provided the significant early benefit of using the large tailings storage capacity provided by the dish-shaped tailings surface in the South TSF.

\section{$2.4 \quad$ Interim storage}

A western extension to the South TSF was designed in early 2006 and constructed in the later part of 2006 and into early 2007. The extension (the interim storage) comprised a hill side storage layout with a decant dam located on the southern side of the existing TSF. Due to layout constraints, a pump-out facility was installed for the interim storage and an emergency spillway was constructed to discharge water into the decant dam. The decant dam was designed with two compartments and was sized for runoff from the extension area.

Deposition of thickened tailings into the interim storage commenced in early 2007, at which time deposition of tailings into the South TSF ceased. The interim storage was initially operated by discharge from its northern side and then later a causeway was constructed into the central area to form a central mound of tailings. Water management efficiency was not optimum for the interim storage due to its approximately rectangular shape but it provided storage capacity for a period of approximately 2.5 years, during which time the tailings beach in the South TSF was given time to dry and desiccate. An aerial photograph showing the clearing works for the interim storage, as well as the shape of the decant dam, is presented in Figure 2.

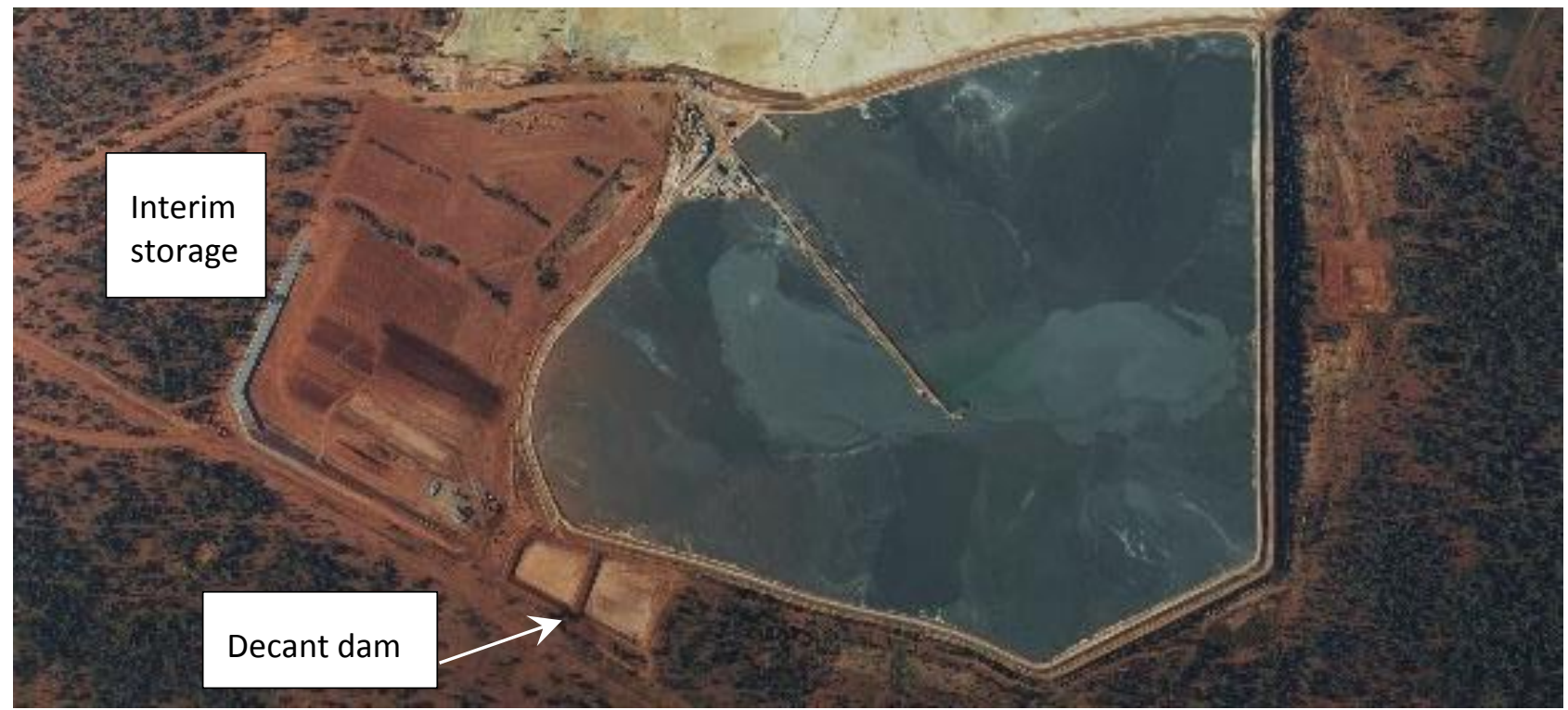

Figure 2 Aerial photograph of the South TSF during construction of the interim storage, September 2006 


\section{$3 \quad$ Initial design planning}

\subsection{Design drivers}

Taking cognisance of the operational challenges of the existing TSF described previously, the following factors were considered in developing the initial transition design layout:

- Drainage: The irregular shape of the perimeter discharge TSF would result in ponding of water if the perimeter embankment was raised along its existing alignment and a central mound of tailings was developed. An alternative embankment layout would be required to form a runoff drainage path around the periphery of the new tailings mound.

- Embankment stability: The eastern embankment of the facility represented the highest point of the perimeter containment, at a height of approximately $20 \mathrm{~m}$. The downstream slope of this embankment was relatively steep and a pond located adjacent to it would potentially result in a phreatic surface that would negatively impact its slope stability.

- Flood management and decant of water: A considerable flood storage volume existed on the dish-shaped surface of the old perimeter tailings beach layout. Mounding of tailings in the central area would progressively diminish flood storage capacity on the surface. Ponding of water would likely form a ring shape around the tailings mound unless carefully managed.

- Tailings beach slope: The gradient of the tailings beach slopes achieved in the interim storage were measured at approximately 1.5 to $2 \%$. These were measured over a beach slope somewhat shorter than the expected beach slope under the proposed CTD layout.

\subsection{Design concept}

\subsubsection{First phase - eastern mound}

A horseshoe-shaped embankment (perimeter embankment raise) was designed over the surface of the old tailings, with a causeway to the crest of the proposed tailings mound. The design tailings beach profile was for an average gradient of $1.5 \%$. The embankment and causeway were configured to suit a tailings mound for a nominated storage period based on forecast tailings deposition data and the adopted beach slope. The open part of the horseshoe configuration was facing the decant dam. The end of the causeway was offset to the northeast from the centre to develop a variable elevation around the inside edge of the perimeter embankment to direct runoff drainage towards the decant dam.

To facilitate drainage of the runoff trapped on the surface of the existing dished tailings surface and the new thickened tailings mound, an open channel was designed in the existing tailings beach. The open channel was designed to drain to a point adjacent to the existing perimeter embankment, where a decant outfall pipe was installed through the embankment. The outfall pipe was configured to discharge supernatant and rainfall runoff into the decant dam. An emergency spillway was also designed for the controlled release of surface water in the event of high rainfall that exceeded the pipe discharge capacity. An upgrade to the decant dam to include an additional compartment, was designed to provide additional flood storage capacity for the TSF. The active compartment of the decant dam was also lined to reduce seepage losses from the dam.

\subsubsection{Second phase - western mound}

A second phase of CTD storage was developed that would see an additional tailings mound developed over the interim storage area after filling of the eastern mound. The horseshoe embankment around the eastern mound would be extended to wrap around the western mound. The alignment would be configured to direct drainage to a modified decant structure on the southern side of the facility, as well as to the emergency spillway developed for the first phase. Development of the second mound would ultimately provide the flexibility to alternate the discharge of tailings between the two mounds to enable drying of the deposited tailings. 


\section{Design development and implementation}

\subsection{Initial eastern mound}

The eastern mound of tailings was to be formed following construction of the perimeter embankment, the tailings causeway, the gravity decant system and the decant dam expansion. To delay capital expenditure, it was decided to delay the perimeter embankment construction and decant dam expansion and commission the eastern mound by constructing the causeway and gravity decant system only. This approach was considered acceptable on the basis that a minimum flood storage capacity was maintained on the old tailings surface and that the tailings mound did not encroach on the footprint of the proposed embankment raise footprint.

In early 2010, the tailings deposition causeway was constructed, a discharge channel excavated into the tailings beach and an outfall pipe was installed through the perimeter embankment. An aerial view of the South TSF following commencement of central discharge of tailings is shown in Figure 3.

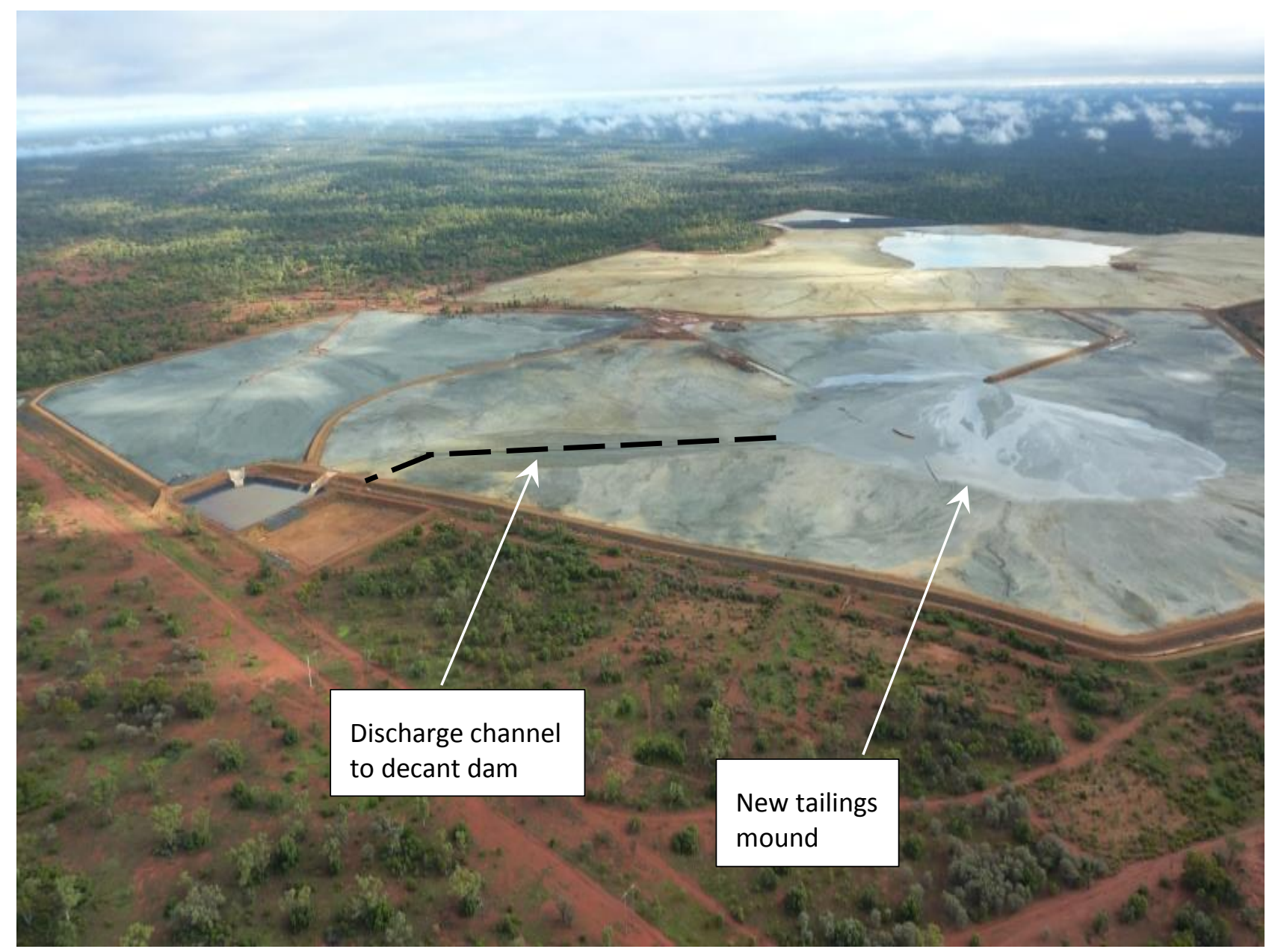

Figure 3 Aerial view of the site TSFs in early 2010, with the South TSF in the foreground

The discharge channel can be seen in Figure 3, located between the new tailings mound and the decant dam. A series of filter berms were installed in the discharge channel to limit tailings from flowing to the outfall pipe located at the old perimeter embankment. A portion of the channel located adjacent to the embankment was lined with a geomembrane liner to limit the risk of seepage from water in the channel. A valve chamber for the outfall pipe, filter curtain and seepage depressurisation system was installed around the pipe where it passes through the embankment. 


\subsection{Eastern mound perimeter embankment}

Prior to the new tailings mound reaching the proposed embankment raise footprint, the remainder of the first phase of construction works commenced. The perimeter embankment was configured to be approximately $0.5 \mathrm{~m}$ above the predicted tailings mound surface at the end of the first phase and to provide drainage towards the decant and spillway structures.

The additional compartment of the decant dam was excavated to the east with new spillways between the compartments. An aerial photograph showing the South TSF layout towards the end of the first phase of construction is presented in Figure 4.

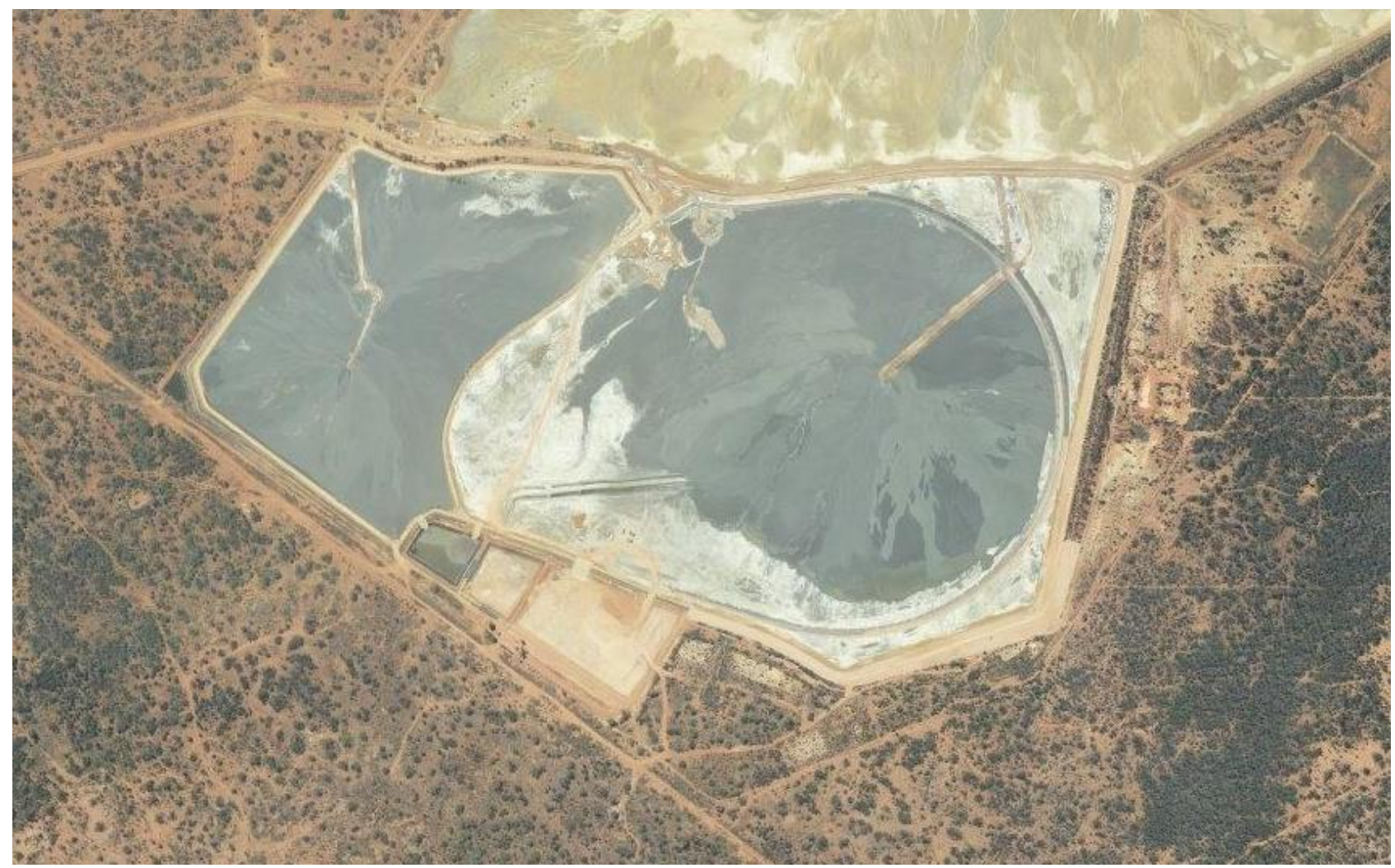

Figure 4 Aerial photograph of the South TSF showing the interim storage and the eastern mound, February 2011

\subsection{Western mound preliminary works}

During filling of the eastern mound, a design was prepared for a western mound over the interim storage area. Similar to the eastern mound, the design included a perimeter embankment and deposition causeway, shaped for runoff towards the water management structures. The perimeter embankment was widened in the area of the supernatant pond, to facilitate a 'top hat' raise and extension of the decant system for a scheduled future raise to the embankment.

The decant system was modified by an upstream extension to the existing outfall pipe and installation of two chutes on the upstream slope of the widened embankment, both connected to the extended outfall pipe. Two chutes were required to maximise water recovery and to allow for the significant movement of the supernatant pond following development of the western mound.

To arrest the effect of embankment cracks due to upstream construction onto the tailings beach and to manage the intermittent ponding of supernatant water adjacent to the perimeter embankment raise, a filter chimney drain was installed along the centreline of a portion of the embankment raise. The emergency spillway was also raised. 


\subsection{Western mound perimeter embankment}

Raise construction of the perimeter embankment around the western mound occurred in late 2013. This raise was joined to the perimeter embankment around the eastern mound. The shape of the embankment was optimised to direct surface water runoff from the tailings beach to a single area. The supernatant pond was located between and on the southern side of the two tailings mounds, where the decant structure and emergency spillway are located. Similar to the perimeter embankment for the east mound, the perimeter embankment crest elevation was variable, designed to be approximately $0.5 \mathrm{~m}$ above the design tailings beach and approximately $1 \mathrm{~m}$ above the spillway invert in the supernatant pond location.

\subsection{Raises to the eastern and western mounds}

By the time it was necessary to construct an additional raise to the perimeter embankment, tailings deposition on both the eastern and western mounds had occurred and the supernatant pond location was stabilising around the eastern chute, as intended by the design. The raise works to the perimeter embankment around the eastern mound, including decant structure and spillway raises, commenced in late 2014 and occurred in two phases with an approximate seven month break in between. The break allowed for drying of the western mound tailings beach prior to its perimeter embankment raise.

An aerial photograph of the South TSF, as at mid-2015, is shown in Figure 5. It shows the perimeter embankment around both tailings mounds.

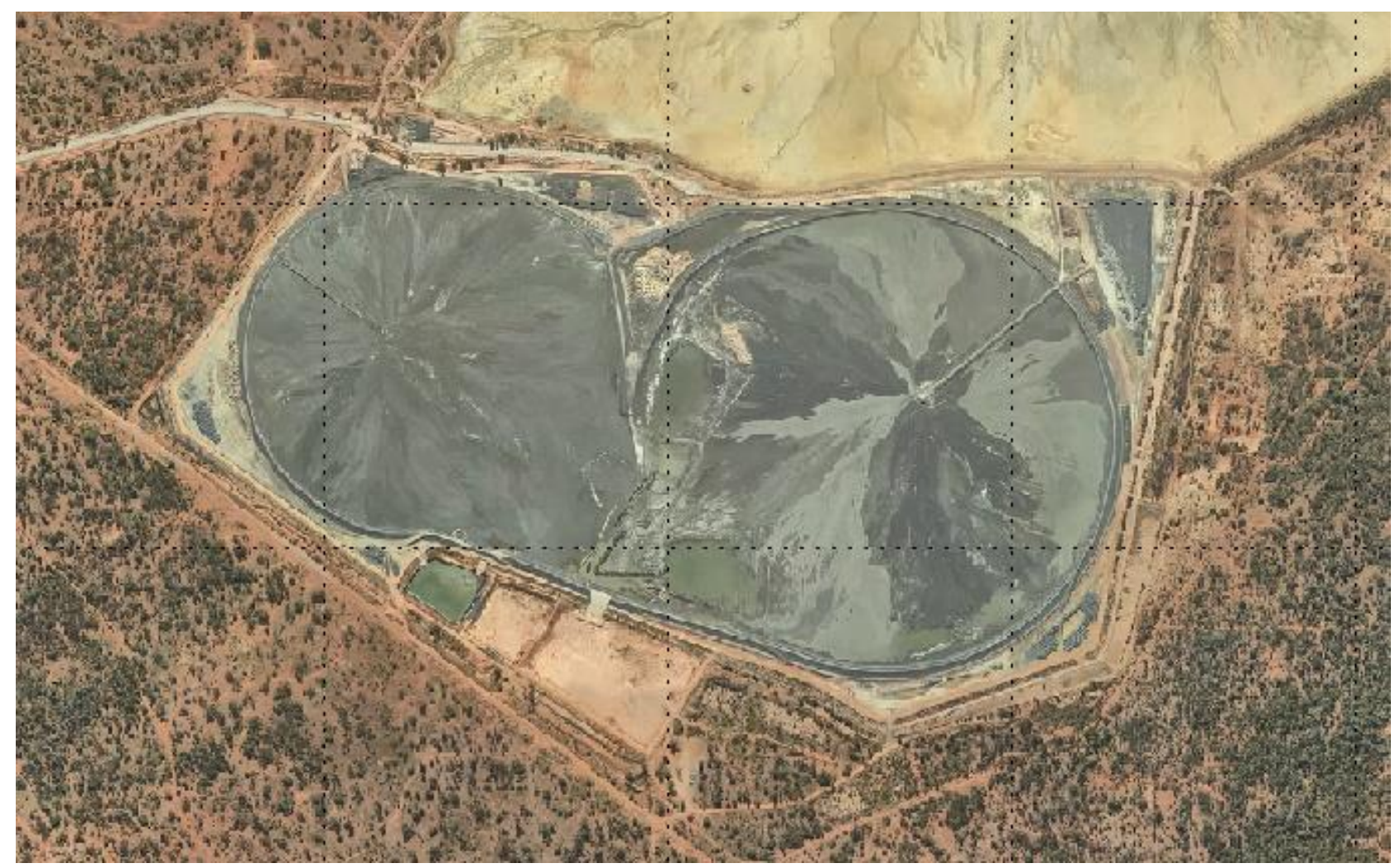

Figure 5 Aerial photograph of the South TSF, August 2015 


\section{$5 \quad$ Design, operation and closure considerations}

\subsection{Tailings discharge method}

Causeways are used to locate the tailings delivery to the crest of the two mounds. The causeways are also designed to be approximately $0.5 \mathrm{~m}$ above the predicted tailings beach for each phase of operation. At the end of each causeway, a small horseshoe configuration of spigots is used to distribute tailings discharge over the mound surface. The tailings discharge is managed so that tailings accumulates in thin layers with periods of drying for each layer, allowing for drying and desiccation before a subsequent layer of tailings is deposited. The tailings deposition is also managed to avoid depressions forming at the periphery of the mound that could result in ponding of supernatant and/or rainfall runoff.

\subsection{Surface water management}

\subsubsection{Surface runoff}

The alignment of the perimeter embankment promotes drainage of both supernatant and rainfall runoff to the gravity decant structure and the emergency spillway. Maintaining a continuous downward gradient around the mound perimeter is achieved by controlled cycling of tailings deposition. Periodic surveys of the tailings beach, typically on a quarterly basis, have allowed for review of the effectiveness of the drainage and implantation of changes to the deposition strategy as required.

\subsubsection{Gravity decant structure}

Selection of a gravity decant system has proved to be effective for the efficient management of surface water from the tailings beach. The position of the decant structure inlet has been optimised through tailings beach modelling and the predicted location of the supernatant pond. The system relies on the progressive placement of concrete lids over the chute in advance of the rising tailings beach. Maintaining a minimum $300 \mathrm{~mm}$ freeboard above the tailings surface has proved to be effective with limiting the potential release of tailings with the supernatant water to the decant dam.

\subsubsection{Emergency spillway}

The emergency spillway is formed within the perimeter embankment raises. To limit the potential for erosion of the underlying embankments during discharge events, the spillway is lined with a reinforced concrete slab and an energy dissipation basin at its toe. A subgrade depressurisation system is also installed under the concrete slab to reduce potential uplift pressures acting on the spillway slabs. The spillway is sized in accordance with regulated design criteria for the dam safety consequence category assigned to the TSF.

\subsection{Tailings beach slopes, storage capacity and layout optimisation}

Topographical surveys of the TSF are typically undertaken on a quarterly basis. These provide an opportunity to review changes in tailings beach slopes, the average tailings dry density and the remaining storage capacity to facilitate scheduling of the next embankment raise. Since the CTD transition began, general steepening of the beach slope has been observed. Steepening of the tailings mound profile is attributed to a number of factors, including the spigot arrangement developed by the operators, increases in slurry solids concentration by improvements made at the thickener, and the flexibility provided by cycling tailings discharge around a centrally formed mound and switching between the east and west mounds.

As of October 2017, the tailings beach profile was characterised by a slope gradient of up to $5 \%$ near the crest of the mound and progressively flattening to approximately $1 \%$ near the periphery. In response, the causeways have been raised and extended to further optimise the TSF storage related to the as-constructed perimeter embankments, while maintaining operational freeboard at the perimeter embankment and runoff drainage towards the water management structures. 
Relative storage capacity with subsequent raises has diminished as each raise results in a smaller mound footprint due to upstream raises. An ultimate raise height for the facility has been selected to manage the progressively increasing rate of rise for tailings deposition as the storage area diminishes.

\subsection{Closure considerations}

The runoff shedding CTD layout limits the potential for water ponding on the tailings surface and thereby vastly reduces the potential for and magnitude of seepage during operation and at closure. Transitioning to the CTD layout required re-configuring the perimeter embankment to direct drainage to the mid-southern area of the TSF. The current alignment and location of the perimeter embankments have resulted in some of the old embankment and tailings beach areas being available for reshaping and rehabilitation. These areas are also being considered for mine waste rock storage as part of the rehabilitation of the areas.

At CSA Mine, integration of waste rock into the TSF design has negated the need to develop an additional, dedicated waste rock storage site that was otherwise required. It also allows for profiling of the outer slopes and buttressing of the old perimeter embankment (where required) which is tied into the closure design.

Tailings in the South TSF are classified as non-acid forming, and the final treatment strategy for the tailings surface at closure is therefore focused on managing the risk of erosion via surface water and wind. Under the concept closure plan, the emergency spillway will be upgraded at closure to accommodate closure design flow requirements.

\section{Summary and conclusions}

The South TSF at CSA Mine was operated as a perimeter discharge facility up until early 2007 when an interim storage was commissioned and the process of transitioning to a CTD layout commenced. The design for the CTD layout was developed based on operational experience of discharging thickened tailings into the interim storage. It was initially implemented with an eastern mound for central discharge and then later a second, western mound. The dual-mounded system provides flexibility to cycle tailings discharge between storage areas, allowing for extended periods of tailings beach drying prior to perimeter embankment raise construction around the respective mound. The layout is optimised for surface water runoff to drain to a small supernatant pond area and to be discharged via a gravity decant structure during normal operation. An emergency spillway is included for flows from high-intensity rainfall.

Transitioning an old perimeter discharge TSF to CTD has allowed the mine to minimise their surface development footprint. The CTD layout has resulted in storage efficiency through the transition phase by forming a mound of tailings over a dish-shaped surface. The runoff shedding tailings mounds provide a more desirable landform for closure than the original dish-shaped tailings surface. The feasibility of transitioning a perimeter discharge TSF is largely dependent on the TSF layout shape and the ability to manage surface water both during the transition and longer term operational phases.

\section{Acknowledgement}

The authors thank Cobar Management Pty Ltd for the supply of photographs and for working closely with the designers of the transition design to ensure its successful implementation. 
